\title{
Eurolntervention
}

\section{Impact of dye injection on intracoronary pressure}

\author{
Martin Stoel*, MD; Jasveen Kandhai-Ragunath, MD; Gert Van Houwelingen, MD; \\ Clemens Von Birgelen, MD, PhD \\ Thorax Centre Twente, Medisch Spectrum Twente, Enschede, The Netherlands
}

\section{KEYWORDS}

Angiography, coronary flow, coronary artery disease

\begin{abstract}
Aims: Coronary angiography is widely used to estimate coronary blood flow velocity, as in the TIMI frame count method. However, it is unknown to what extent the injection of dye elevates intracoronary pressure which may accelerate coronary blood flow velocity. In the present study, intracoronary pressure was measured during coronary angiography.

Methods and results: In 25 patients with non-significant coronary lesions, assessed by fractional flow reserve measurement with a pressure guidewire, we recorded intracoronary pressure during dye injection for coronary angiography in the ostium of the coronary artery as well as distal to the lesion. There was a rise in mean intracoronary pressure during dye injection in both ostial and distal coronary arterial segments (from $90.8 \pm 17.2 \mathrm{mmHg}$ to $96.8 \pm 18.5 \mathrm{mmHg}$ and from $89.7 \pm 15.3 \mathrm{mmHg}$ to $93.6 \pm 17.3 \mathrm{mmHg}$, respectively; $p<0.001)$. Nevertheless, the absolute and relative increase in pressure was small $(6.0 \pm 4.2 \mathrm{mmHg}\{6.7 \pm 4.9 \%\}$ in the ostium, and $3.9 \pm 5.5 \mathrm{mmHg}\{4.2 \pm 5.7 \%\}$ distally).

Conclusions: In coronary arteries without significant stenosis, coronary angiography causes only a minor increase in intracoronary pressure. The limited impact of dye injection on intracoronary blood pressure confirms the value of coronary angiography for estimation of coronary flow velocity.
\end{abstract}

\footnotetext{
* Corresponding author: Thorax Centre Twente, Medisch Spectrum Twente, Department of Cardiology, Medisch Spectrum Twente, PO Box 50 000, Enschede, The Netherlands

E-mail:m.stoel@ziekenhuis-mst.nl

(C) Europa Edition. All rights reserved.
} 


\section{Introduction}

Coronary blood flow velocity can be estimated from coronary angiography by measuring TIMI frame count (TFC) ${ }^{1,2}$ and TIMI frame count velocity $(\mathrm{FCV})^{3,4}$. Previous studies showed that both size of the guiding catheter ${ }^{5}$ and rate of contrast injection ${ }^{6,7}$ do not significantly alter TFC. Nevertheless, during angiography, the force of dye injection could temporarily elevate intracoronary pressure to some extent, which may increase coronary blood flow velocity. Coronary blood flow during dye injection has previously been studied $^{8}$, but we are not aware of a study that may have prospectively investigated the effect of dye injection on (proximal and distal) intracoronary pressure in human coronary arteries in vivo. We therefore studied this relationship during standard coronary angiography procedures.

\section{Methods}

\section{Study population}

We examined a total of 25 consecutive patients, who were in sinus rhythm and scheduled for fractional flow reserve (FFR) measurement of an intermediate coronary lesions which turned out to be insignificant (FFR>0.75). Patients with atrial fibrillation, anatomically significant ostium stenosis (diameter stenosis $>50 \%$ by quantitative coronary angiography) or damping of the pressure curve were not considered for inclusion.

\section{Interventional procedure}

All patients were examined through the femoral artery using $6 \mathrm{Fr}$ guiding catheters without side holes (Cordis Europa, Roden, The Netherlands) and received a bolus of $5.000 \mathrm{IU}$ of heparin and an intracoronary bolus of 200-300 $\mu \mathrm{g}$ of nitroglycerin. The contrast medium lodixanol (Visipaque 320, Amersham Health, Eindhoven, The Netherlands) was used for coronary angiography with manual dye injections. We performed standard quantitative coronary angiography (QCA) analyses (Pie Medical Imaging, Maastricht, The Netherlands) of the proximal and distal reference vessel segments and the target lesion.

\section{Pressure recordings and analysis}

Pressure sensor-equipped guidewires (Radi Medical Systems, Uppsala, Sweden) that permit intracoronary pressure tracings without flow obstruction were used to measure intracoronary pressure as previously described ${ }^{9-13}$. FFR was determined after bolus injection of $50 \mu \mathrm{g}$ of adenosine into the right coronary artery and $100 \mu \mathrm{g}$ into the left coronary artery. After coronary hyperaemia was no longer present, coronary angiography was accomplished. During dye injection we performed simultaneous measurements of both the pressure inside the coronary arteries (by the pressure sensor on the pressure guidewire) and the pressure in the proximal part of the guiding catheter (by the fluid filled pressure sensor on the manifold). The pressure sensor of the guidewire was positioned, first distally to the target lesion and secondly, in the proximal segment of the coronary artery just a few millimetres distal to the ostium. Systolic and diastolic arterial pressure was recorded digitally for both sites. All pressure recordings started at least one cardiac cycle before the dye injection and ended after at least one cardiac cycle after contrast injection was finished. In Figure 1, a typical pressure tracing during the injection of dye is shown. The mean arterial pressure (MAP) was calculated as: (1x systolic pressure $+2 x$ diastolic pressure) divided by 3 .

In an additional group of six patients, intracoronary pressure during dye injection was recorded at the coronary ostium as well as in the coronary artery at a distance of 3, 6 and $9 \mathrm{~cm}$ from the ostium. These distances were determined by the length of the radio-opaque distal part of the pressure guidewire.

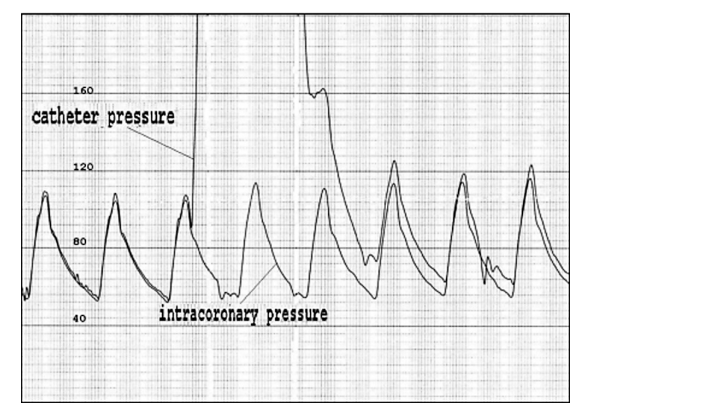

Figure 1. Example of catheter and pressure guidewire tracings $(\mathrm{mmHg})$ during dye injection with pressure sensor located in left main coronary artery, showing minor elevation of intracoronary pressure during injection of approximate $10 \mathrm{mmHg}$.

\section{Statistical analysis}

Analyses were performed with SPSS 16.0 (SPSS Inc., Chicago, IL, USA). Dichotomous data are presented as frequencies. Quantitative data are presented as mean $\pm 1 S D$ and compared using repeated measurements analysis (Random intercept) with post hoc comparisons according to the method of Sidak. A p-value $<0.05$ was considered significant.

\section{Results}

The characteristics of the 25 patients are presented in Table 1. The procedure and lesion characteristics are shown in Table 2. There were 21 measurements in the left main coronary artery (LCA), five in the ostium of the right coronary artery (RCA) and 32 measurements distal to intermediate lesions (17 left anterior descending (LAD), 10 left circumflex ( $L C X)$, and five RCA). In one patient, measurements were performed in the LCA as well as in the RCA, and in six patients measurements were performed both in LAD and LCX. Table 3 shows the systolic, diastolic, and mean intracoronary pressure before, during and after dye injection, both in the coronary ostium and distal to the intermediate lesion. During dye injection there was an increase in systolic and diastolic blood pressure (mean pressure from $90.8 \pm 17.2 \mathrm{mmHg}$ to $96.8 \pm 18.5 \mathrm{mmHg}, \mathrm{p}<0.001$ for ostial pressure measurements, and from $89.7 \pm 15.3 \mathrm{mmHg}$ to $93.6 \pm 17.3 \mathrm{mmHg}$, $\mathrm{p}<0.02$ for distal measurements). Nevertheless, this increase remained small. The mean pressure in the ostium of the coronary artery increased during dye injection by $6.0 \pm 4.2 \mathrm{mmHg}(6.7 \pm 4.9 \%)$, while distal to the insignificant lesion the intracoronary pressure increased by $3.9 \pm 5.5 \mathrm{mmHg}(4.2 \pm 5.7 \%)$. There were no significant 
Table 1. Patient characteristics.

\begin{tabular}{lc}
\hline Patients, $n$ & 25 \\
Age, y & $64 \pm 9.8$ \\
Male, \% & 80 \\
Diabetes mellitus, \% & 12 \\
Hypertension, \% & 40 \\
Dyslipidaemia, \% & 40 \\
Smoker, \% & 24 \\
Family history of coronary disease, \% & 32 \\
Medication, \% & \\
$\quad$ Acetylsalicylic acid & 100 \\
$\quad$ Beta blockers & 68 \\
$\quad$ ACE inhibitors & 76 \\
$\quad$ Calcium channel blockers & 44 \\
$\quad$ Nitrates & 40 \\
Previous myocardial infarction, \% & 32 \\
Previous CABG, \% & 12 \\
Previous PCI, \% & 0 \\
\end{tabular}

ACE: angiotensin-converting enzyme; CABG: coronary artery bypass grafting; PCI: percutaneous coronary intervention

Table 2. Lesion and procedure characteristics.

\begin{tabular}{|c|c|c|c|}
\hline & All $0 \mathrm{~s}$ & Ostial $(n=26)$ & Distal $(\mathrm{n}=32)$ \\
\hline $\mathrm{LCA}, n$ & & 21 & - \\
\hline $\mathrm{LAD}, n$ & & - & 17 \\
\hline $\mathrm{LCX}, n$ & & - & 10 \\
\hline $\mathrm{RCA}, n$ & & 5 & 5 \\
\hline Vessel reference diameter, $\mathrm{mm}$ & & $4.3 \pm 1.1$ & $3.1 \pm 0.4$ \\
\hline Diameter stenosis, \% & & - & $49.2 \pm 5.7$ \\
\hline Systolic blood pressure, $\mathrm{mmHg}$ & $135 \pm 31$ & & \\
\hline Diastolic blood pressure, $\mathrm{mmHg}$ & $68 \pm 11$ & & \\
\hline Heart Rate, bpm & $65 \pm 12.9$ & & \\
\hline FFR & - & & $0.85 \pm 0.07$ \\
\hline
\end{tabular}

LCA: left coronary artery; LAD: left anterior descending; LCx: left circumflex coronary artery; RCA: right coronary artery; FFR: fractional flow reserve

differences for the increase in pressure in the LCA compared to the $\mathrm{RCA}(6.6 \pm 4.4 \mathrm{mmHg}$ and $3.6 \pm 2.8 \mathrm{mmHg}$, respectively, $\mathrm{p}=\mathrm{NS})$.

Figures 2 and 3 illustrate the individual changes in systolic and diastolic pressure for ostial and distal positions of the pressure wire sensor, respectively.

In six patients, intracoronary pressure was recorded at the coronary ostium and in the coronary artery at 3,6 and $9 \mathrm{~cm}$ from the ostium ( 3 LAD, 2 LCx and 2 RCA). The change in mean intracoronary pressure during dye injection compared to the mean pressure before and after injection is shown in Figure 4. Mean change in intracoronary pressure during dye injection, measured

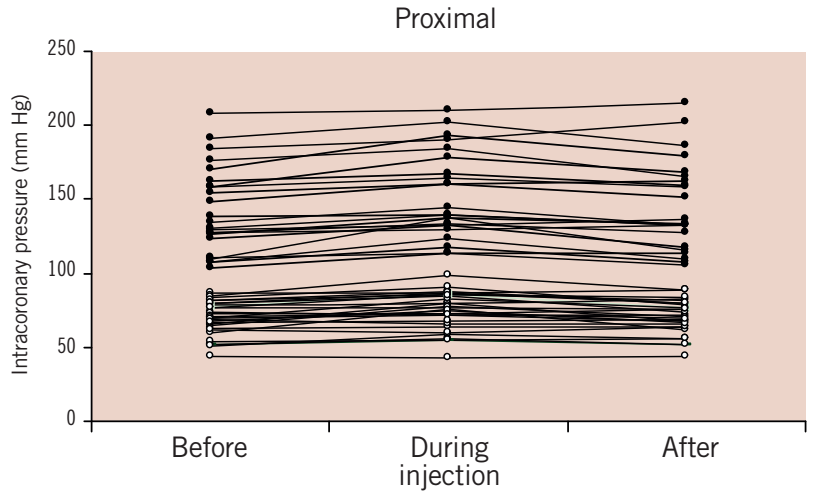

Figure 2. Systolic ( $\bullet$ ) and diastolic (0) intracoronary pressures $(\mathrm{mmHg})$ before, during, and after dye injection for all measurements with the pressure sensor located in the coronary ostium $(n=26)$.

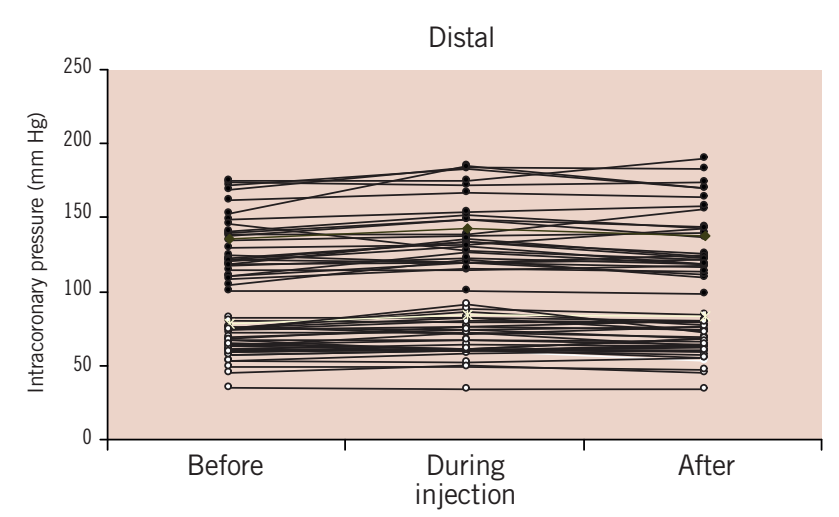

Figure 3. Systolic (•) and diastolic (०) intracoronary pressures $(\mathrm{mm} \mathrm{Hg}$ ) before, during and after dye injection for all measurements with the pressure sensor located distal to the target lesion $(n=32)$.

from proximal to distal was $6.9 \pm 1.2,4.0 \pm 1.4,4.5 \pm 1.3$ and $3.1 \pm 1.5 \mathrm{mmHg}$.

\section{Discussion}

The present study shows that manual injection of dye for coronary angiography causes a measurable, statistically significant rise in intracoronary pressure, which is relatively small and can be observed particularly in the proximal segments of the left and right coronary arteries. In fact, such a small increase in systolic and diastolic pressure is negligible compared to normal variations in blood pressure such as - for instance - that caused by respiration. The results of this study

Table 3. Intracoronary pressure before, during and after dye injection.

\begin{tabular}{|c|c|c|c|c|c|}
\hline & & Before & During & After & $\mathrm{p}^{*}$ \\
\hline \multirow[t]{3}{*}{ Ostial pressure $(\mathrm{mmHg})$} & Systolic & $136.0 \pm 33.6$ & $145.1 \pm 33.9$ & $138.3 \pm 34.8$ & $<0.001$ \\
\hline & Diastolic & $68.2 \pm 11.0$ & $72.6 \pm 12.4$ & $68.9 \pm 10.6$ & $<0.001$ \\
\hline & Mean & $90.8 \pm 17.2$ & $96.8 \pm 18.5$ & $92.1 \pm 17.1$ & $<0.001$ \\
\hline \multirow[t]{3}{*}{ Distal pressure $(\mathrm{mmHg})$} & Systolic & $134.1 \pm 28.9$ & $140.4 \pm 31.1$ & $137.2 \pm 31.7$ & $<0.001$ \\
\hline & Diastolic & $67.5 \pm 10.9$ & $70.3 \pm 13.3$ & $68.7 \pm 12.1$ & 0.016 \\
\hline & Mean & $89.7 \pm 15.3$ & $93.6 \pm 17.3$ & $91.5 \pm 16.8$ & $<0.001$ \\
\hline
\end{tabular}

${ }^{*} \mathrm{p}$ for pressures during dye injection compared to before the injection, and for after dye injection compared to during injection. 


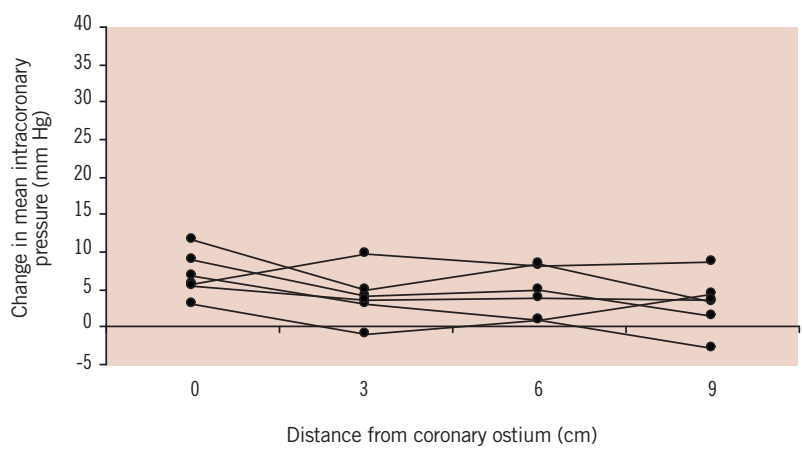

Figure 4. Change in mean intracoronary pressure $(\mathrm{mmHg})$ during dye injection compared to the mean pressure before and after injection, with the pressure sensor located in the coronary ostium and 3, 6 and $9 \mathrm{~cm}$ distal to the ostium ( $n=6)$.

confirm the use of coronary angiography for estimation of coronary blood flow velocity with the TIMI frame count ${ }^{3}$, as well as for the evaluation of microvascular perfusion with the Myocardial Blush Grade $^{14}$. In addition, the manual injection of saline that is used to estimate coronary flow and microvascular resistance ${ }^{15-17}$, is likewise of limited influence on intracoronary pressure and blood flow velocity.

\section{Previous studies}

Our data explain why the rate of dye injection does not significantly influence blood flow velocity, as was shown by Dodge et al and Abaci et $a^{6,7}$ and confirms the value of using coronary angiography to estimate coronary blood flow velocity with TFC and FCV1-4. In addition, the findings of the present study are in accordance with data of Hodgson et al, who found only a small increase $(<1.5 \%)$ in coronary blood flow during the initial phase of dye injection ${ }^{8}$.

\section{Factors that may affect coronary pressure during angiography}

There is a critical ratio between the size of the guiding catheter and the coronary orifice, above which the high pressure inside the guiding catheter (during dye injection) propagates into the coronary artery. The exact value of this critical ratio is unknown. For that reason, it was essential to assure an easy backflow of dye into the ascending aorta during dye injection, which resulted in stable intracoronary pressure. Of note, our study was performed with $6 \mathrm{Fr}$ guiding catheters in coronary arteries without significant ostial disease or damping of the pressure signal in the guiding catheter. In addition, in case of haemodynamic significant coronary stenosis, dye injection may increase proximal intracoronary pressure in a more pronounced fashion as compared to normal coronary arteries. However, we limited our study to the assessment of pressure in coronary arteries without haemodynamically significant coronary stenosis (FFR>0.75 in all vessels studied).

\section{Implications for TIMI frame count}

The rise in mean arterial pressure in the ostium of the coronary arteries during dye injection was $6.0 \pm 4.2 \mathrm{mmHg}$. Compared to baseline, this is an increase by $6.7 \pm 4.9 \%$. In general, the rise in pressure lasts the whole period of time in which the frames for the TFC are counted.
Assuming that coronary resistance (epicardial and microvascular) does not change, this pressure rise should augment coronary blood flow velocity during TFC measurements by approximately $6.7 \%$ (compared to the state before dye injection). Left anterior descending (LAD), left circumflex (LCX), and right (RCA) coronary

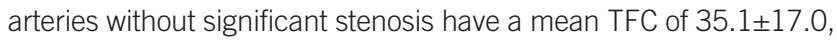
$25.1 \pm 9.5$, and $17.0 \pm 2.5$ respectively ( 25 frames $/ \mathrm{sec})^{4}$.

Consequently, the dye injection for TFC measurement may increase coronary flow velocity and lower TFC, with a decrease on average of 2.3, 1.9 and 1.1 frames for $L A D, L C x$, and RCA respectively, less then corresponding standard deviations.

For the assessment and comparison of the TFC in daily practice and in scientific studies, it makes no sense to perform a correction of the measurements as TFC requires dye injection as an essential part of the method. Nevertheless, we feel that it is interesting to know and take into account the above mentioned facts.

\section{Limitations}

Standard manual dye injection may show more variability in force than an automated dye injection with an injection pump. Nevertheless, the manual approach resembles the routine practice in the vast majority of catheterisation laboratories, both in routine practice and scientific studies, and our findings can be transferred to most clinical scenarios. All measurements were done using $6 \mathrm{Fr}$ guiding catheters. It is possible that the use of $8 \mathrm{Fr}$ guiding catheters causes more pronounced elevation of intracoronary pressure during dye injection. This could be a subject of future studies. In the calculation of mean blood pressure and the relation to coronary flow velocity, the predominant diastolic coronary flow was not accounted for. The higher viscosity of dye as compared to blood may reduce flow velocity to a certain extent; this issue could not be addressed in this clinical study and may not be relevant as it is inherent to the technique. The sample size of 25 patients was not large, but adequate to assess the relation between dye injection and intracoronary pressure. Finally, blood pressure variation caused by respiration could have influenced pressure measurements to a limited degree.

\section{Conclusion}

In coronary arteries without significant stenosis, coronary angiography causes only a minor increase in intracoronary pressure. Our data are in line with previous findings which suggested that the impact of dye injection on coronary blood flow velocity is limited, and confirm the value of coronary angiography for estimation of coronary blood flow velocity.

\section{Acknowledgements}

The authors would like to thank Dr. J. van der Palen, epidemiologist at Medisch Spectrum Twente in Enschede, The Netherlands for his support in the statistical analysis.

\section{References}

1. Gibson CM, Cannon CP, Daley WL, Dodge JT Jr, Alexander B Jr, Marble SJ, McCabe CH, Raymond L, Fortin T, Poole WK, Braunwald E. TIMI frame count: a quantitative method of assessing coronary artery flow. Circulation. 1996;93:879-888. 
2. Barcin C, Denktas AE, Garratt KN, Higano ST, Holmes DR Jr, Lerman A. Relation of Thrombolysis in Myocardial Infarction (TIMI) frame count to coronary flow parameters. Am J Cardiol. 2003;91:466-9.

3. Gibson CM, Dodge JT Jr, Goel M, Al-Mousa EN, Rizzo M, McLean C, Ryan K, Sparano A, Marble SJ, Daley WL, Cannon CP, Antman EM. Angioplasty guidewire velocity: a new simple method to calculate absolute coronary blood velocity and flow. Am J Cardiol. 1997;80:1536-1539.

4. Stoel MG, Zijlstra F, Visser CA. Frame count reserve. Circulation. 2003;107:3034-3039.

5. Vijayalakshmi K, Kunadian B, Whittaker VJ, Wright RA, Hall JA, Somasundram U, Stewart MJ, Sutton A, Davies A, de Belder MA. Impact of catheter sizes and intracoronary glyceryl trinitrate on the TIMI frame count when digital angiograms are acquired at lower frame rates during elective angiography and PCl. Acute Card Care. 2007;9:231-8.

6. Dodge JT Jr, Rizzo M, Nykiel M, Altmann J, Hobkirk K, Brennan M, Gibson CM. Impact of injection rate on the Thrombolysis in Myocardial Infarction (TIMI) trial frame count. Am J Cardiol. 1998;81:1268-1270.

7. Abaci A, Oguzhan A, Eryol NK, Ergin A. Effect of potential confounding factors on the thrombolysis in myocardial infarction (TIMI) trial frame count and its reproducibility. Circulation. 1999;100:2219-2223.

8. Hodgson JM, Mancini GB, Legrand V, Vogel RA. Characterization of changes in coronary blood flow during the first six seconds after intracoronary contrast injection. Invest Radiol. 1985;20:246-252.

9. Serruys PW, Di Mario C, Meneveau N, de Jaegere P, Strikwerda S, de Feyter PJ, Emanuelsson $\mathrm{H}$. Intracoronary pressure and flow velocity with sensor-tip guidewires: a new methodologic approach for assessment of coronary hemodynamics before and after coronary interventions. Am J Cardiol. 1993;71:41D-53D.
10. Kern MJ. Coronary physiology revisited : practical insights from the cardiac catheterization laboratory. Circulation. 2000;101:1344-51.

11. Pijls NH, De Bruyne B, Peels K, Van Der Voort PH, Bonnier HJ, Bartunek J Koolen JJ, Koolen JJ. Measurement of fractional flow reserve to assess the functional severity of coronary-artery stenoses. N Engl J Med. 1996;334:1703-8.

12. De Bruyne B, Pijls NH, Bartunek J, Kulecki K, Bech JW, De Winter H, Van Crombrugge P, Heyndrickx GR, Wijns W. Fractional flow reserve in patients with prior myocardial infarction. Circulation. 2001;104:157-62.

13. Casella G, Rieber J, Schiele TM, Stempfle HU, Siebert U, Leibig M, Theisen K, Buchmeier U, Klauss V. A Randomized comparison of 4 doses of intracoronary adenosine in the assessment of fractional flow reserve. Z Kardiol. 2003;92:627-32.

14. van 't Hof AW, Liem A, Suryapranata H, Hoorntje JC, de Boer MJ, Zijlstra F. Angiographic assessment of myocardial reperfusion in patients treated with primary angioplasty for acute myocardial infarction: myocardial blush grade. Zwolle Myocardial Infarction Study Group. Circulation. 1998;97:2302-6.

15. De Bruyne B, Pijls NH, Smith L, Wievegg M, Heyndrickx GR. Coronary thermodilution to assess flow reserve: experimental validation. Circulation. 2001;104: 2003-2006.

16. Pijls NH, De Bruyne B, Smith L, Aarnoudse W, Barbato E, Bartunek J, Bech GJ, Van De Vosse F. Coronary thermodilution to asses flow reserve: validation in humans. Circulation. 2002;105: 2480-2484.

17. Fearon WF, Balsam LB, Farouque HM, Caffarelli AD, Robbins RC, Fitzgerald PJ, Yock PG, Yeung AC. Novel index for invasively assessing the coronary microcirculation. Circulation. 2003;107:3129-32. 